\title{
Formação de professores de línguas: ensino e práticas digitais
}

\author{
Patricia Vasconcelos Almeida* \\ Helena Maria Ferreira**
}

\section{Resumo}

Considerando a abrangência dos estudos da língua e linguagem em relação ao processo de ensinoaprendizagem e formação de professores de línguas, este artigo tem como foco contribuir para essa área do conhecimento trazendo considerações sobre letramentos e multimodalidade. Tendo como pano de fundo a pesquisa qualitativa e etnográfica no âmbito de um curso de formação de professores, buscaremos apresentar considerações de professores pré-serviço ao vivenciar experiências de ensino de língua inglesa por meio das tecnologias digitais. Ao teorizar reflexivamente sobre sua própria prática didática e a de seus colegas, percebe-se que os participantes demonstram ter certo letramento digital e conseguem visualizar novas possibilidades de explorar a multimodalidade para e na execução das atividades de ensino propostas.

Palavras-chave: ensino-aprendizagem, língua inglesa, tecnologias digitais.

\section{Language Teachers Training: teaching and digital practices}

\section{Abstract}

Considering the range of language studies in relation to the teaching-learning process and language teachers training, this article aims to contribute to this area of knowledge by bringing considerations about literacy and multimodality. Through qualitative and ethnographic research in a teacher training course, it will be presented considerations of pre-service teachers' considerations about the moment they experienced teaching English through digital technologies. By a reflective approach the participants were able to theorize about their own didactic practice and also the ones from their colleagues. Analyzing this process it was clear that the participants demonstrated that they have some digital literacy and they are able to visualize new possibilities to explore multimodality for and in the execution of the proposed teaching activities.

Keywords: teaching-learning, english language, digital technologies.

\section{Introdução}

Refletir sobre o ensino de línguas estrangeiras (LE) e seus desafios constitui uma tarefa notadamente complexa, o que demandaria mais páginas do que um artigo pode comportar. No entanto, salvaguardadas as peculiaridades desse campo de ensino, delimitamos o foco de nosso artigo na dimensão multissemiótica da linguagem e

\footnotetext{
* Professora da Universidade Federal de Lavras, Departamento de Estudos da Linguagem; profa. no programa de Mestrado Profissional em Educação. E-mail: patricialmeida@del.ufla.br.

** Professora do Departamento de Estudos da Linguagem da Universidade Federal de Lavras, Coordenadora e docente do programa de mestrado profissional em educação. E-mail: helenaferreira@del.ufla.br.
} 
investimos na reflexão sobre as habilidades relacionadas aos multiletramentos no âmbito de um curso de formação inicial de professores. Desse modo, o objetivo do presente trabalho é socializar experiências formativas vivenciadas por professores em pré-serviço e analisá-las sob a perspectiva dos multiletramentos/multimodalidade.

Nesse escopo, merecem destaque questões que abrangem o material didático, o ambiente de ensino, as metodologias, as políticas públicas, enfim, aspectos que colaboram para a compreensão da configuração atual do ensino de LE, que, incontestavelmente, faz uso das tecnologias digitais.

Sem a pretensão de esgotar o assunto ou dar conta de todos esses vieses em que os estudos sobre o ensino de LE perpassam, temos o propósito discursivo de contribuir para uma reflexão acerca do processo de ensino-aprendizagem de língua estrangeira, enfocando questões ligadas à multimodalidade, à multissemiose e aos multiletramentos.

\section{O ensino de LE na era da multimodalidade}

O ensino de LE tem suas bases históricas marcadas no início de 1930, quando o contexto político e econômico do Brasil passou a considerar sua importância para o desenvolvimento do país. Legislações surgiram a fim de organizar o ciclo de um ensino que vislumbrava o crescimento de oportunidades educativas.

Diversos métodos e abordagens de ensino (RICHARDS \& RODGERS, 1983; ELLIS, 1997; KURAMAVADIVELU, 2006), principalmente, direcionados às línguas estrangeiras surgiram e foram se modificando de acordo com as demandas sociais e pedagógicas e reconfigurados a partir das pesquisas e das publicações acadêmicas, notadamente, na área da Educação e da Linguística Aplicada.

Nas últimas décadas do século passado, as pesquisas e as práticas de ensino relacionadas às LE passaram a dinamizar um processo de readequação desses métodos e abordagens, levando em consideração as influências diretas de ferramentas (tecnologias) na pedagogia de línguas.

Buscando evidenciar essas influências, Paiva (2015:3) traça um histórico sobre o uso de tecnologias para o ensino de línguas e apresenta uma concepção bastante ampliada, que permite uma visão processual dessa trajetória. A autora inicia a historização com o período em que os professores de línguas, atendendo os métodos e as abordagens, utilizavam o quadro negro, giz e o livro didático e destaca que existia 
uma crença de que "aprender uma língua significava aprender a sintaxe dessa língua". Por essa razão, durante muito tempo se investiu em produções de livros que priorizavam a aquisição de vocabulário e de estruturas frasais. Posteriormente, surgiram o gravador e a fita cassete, fazendo emergir metodologias que utilizam de áudio e vídeo. Nesse contexto, segundo Paiva (2015), o ensino passa a dar primazia para a produção da língua falada. Com a evolução tecnológica, as televisões passaram a ser utilizadas em conjunto com os aparelhos de vídeos e, com tais aparatos, irromperam expectativas para minimização do desinteresse, da indisciplina ou de dificuldades de aprendizagem dos alunos. No entanto, tais expectativas não se efetivaram em função dos vários outros elementos intervenientes no processo educativo. Logo esses recursos também foram sendo superados pelos computadores e seus softwares, que demandavam espaços específicos, para além das salas de aulas tradicionais, bem como novos investimentos metodológicos.

Com a globalização e o avanço da rede mundial de computadores, surgem, então, as ferramentas digitais, tais como computadores de mesa conectados à Internet, computadores pessoais portáteis, tablets, telefones etc. Tais tecnologias, por sua vez, não representam apenas mais possibilidades de acesso às formas de linguagem, elas demandam novos saberes didáticos, novas metodologias e novas pesquisas.

Diante do exposto, evidencia-se que essa multiplicidade de ferramentas estabelece a possibilidade de inúmeros cenários de ensino, com vistas a minimizar a distância entre a língua-alvo e a realidade dos aprendizes. Essas novas abordagens requerem uma ressignificação dos processos de ensino, emanando nova postura do aluno-aprendiz, que passa a assumir uma atitude ativa e novas condições de autonomia, ou seja, ele passa a controlar o seu próprio aprendizado para maximizar todo o seu potencial e a se responsabilizar pelo próprio aprendizado (Paiva, 2015). Com acesso a vários inputs para buscar outros meios de utilizar a língua-alvo, o aluno passa a se “expor" voluntariamente a outras experiências de comunicação por meio das tecnologias digitais e seus diversos recursos e se depara com a possibilidade de interagir, criar, trocar e se formar um usuário da língua-alvo.

Esse processo de autonomia do aprendiz, juntamente com a consciência de que as tecnologias digitais passam a oferecer outras possibilidades para o processo de ensino-aprendizagem de línguas, qual seja, as potencialidades de um ensino a distância, 
que foi reconfigurado, em função das possibilidades oferecidas pelas tecnologias digitais (Braga, 2013), potencializou o uso de plataformas virtuais.

As demandas sociais não pararam em relação ao ensino de LE e assim surgiu também o ensino híbrido de línguas, em que o professor ou a instituição oferece oportunidades de aprendizagem presenciais e a distância, sendo o tempo dividido entre elas, determinado e supervisionado pelo professor, mas também controlado pelo aprendiz (SILVA; CAMARGO, 2015; SUNAGA; CARVALHO, 2015; ALBUQUERQUE-COSTA; MAYRINK, 2015). A hibridização tem sido uma inconteste estratégia para o ensino de LE, pois em pleno século XIX, no auge da disseminação do acesso às tecnologias digitais, os contextos educacionais perscrutam mecanismos para acesso aos usos da linguagem de modo a contemplar as diferentes práticas linguístico-discursivas, os conhecimentos socialmente construídos na constante interação com o outro, para além dos espaços escolares. Esse uso busca implantar uma atitude ativa por parte do aprendiz, que precisa perceber que aprender uma língua é interagir, é desenvolver capacidades discursivas em diferentes contextos e construir sentidos coletivamente, é dar condições ao sujeito de "viver", de posicionar-se, de expressar-se nas mais variadas circunstâncias comunicativas e com o maior número possível de interlocutores, recriando e/ou reproduzindo, dentro delas, espaços de diálogos e de representação de discursos presentes no meio social.

Esse cenário contemporâneo desafia os profissionais do ensino e os convida a (re)configurarem sua prática pedagógica. Nesse contexto, destaca a necessidade de compreensão das questões epistemológicas e axiológicas que envolvem a multimodalidade e os multiletramentos, possíveis e facilitados pelas tecnologias digitais.

Vale destacar os estudos dos autores como Levy (1997), Paiva (1997), Hubbard (2004), Braga (2013), Leffa (2016), os quais desenvolveram trabalhos qualitativos que se configuraram em uma determinada época e em um contexto específico. Esses autores estavam preocupados em compreender o potencial do ensino multimídia para o ensino de línguas, buscando incentivar o professor e o aprendiz a inserir as tecnologias digitais no seu fazer pedagógico e no seu processo de aprendizagem respectivamente. Eles buscam difundir o conhecimento epistemológico das potencialidades e desafios provenientes da internet para o ensino de línguas. 
Isto posto, percebemos que as perspectivas e os desafios frente ao uso das tecnologias digitais no contexto educacional não são novas, mas a cada momento elas se transformam de acordo com os contextos histórico-sociais em que pesquisadores, educadores e aprendizes estão inseridos. Por essa razão, é importante manter uma constante reflexão sobre as práticas de linguagem e os (multi)letramentos nos ambientes de ensino multimodais, visto que uma visão mais crítica ressignifica a compreensão da sistemática atual que envolve o ensino de línguas e linguagens, ou seja, as práticas didático-pedagógicas que o constituem.

\section{Do letramento aos multiletramentos}

O intuito desta seção não é re(apresentar) as definições de letramento e suas variadas "sub" denominações de acordo com cada área do conhecimento, mas apontar as diretrizes e os fundamentos teóricos que nortearam as análises dos dados selecionados para este artigo. Isto posto, devemos dar destaque no que postula Baron (1994) e que foi ressaltado por Barton e Lee (2015: 242) da seguinte forma: "proposições sobre práticas de letramento feitas duas décadas atrás já deixaram claro que o letramento é historicamente situado e que as práticas de letramento mudam."

De acordo com os autores supramencionados, se considerarmos as tecnologias digitais, que são atualizadas em um menor espaço de tempo, e o que as pessoas fazem com elas e a partir delas a fim de construir sentidos em suas atividades cotidianas, é necessário inserir as práticas de letramento no cotidiano do ensino de línguas, que é influenciado pelas transformações culturais, sociais, políticas e tecnológicas. Para analisar essas transformações, precisamos compreender também o conceito de letramento crítico que, segundo Green (1998), demanda dos indivíduos mais do que fazer uso de práticas de letramento, mas principalmente transformar essas práticas.

Essa posição vem ao encontro dos preceitos de Brydon (2011), que ressalta a necessidade de pensar criticamente sobre as práticas de letramento. Isto é, é preciso que os indivíduos em suas práticas de letramento sejam capazes de contextualizar, analisar, adaptar e modificar suas interações dentro e além de sua comunidade. Dessa forma, temos de considerar importantes para este contexto de investigação as influências do campo do conhecimento que envolvem a teoria sociocultural da linguagem, visto que estamos lidando com o ensino de LE e ele demanda o desenvolvimento de várias 
habilidades simultaneamente, bem como a articulação com o contexto sociodiscursivo em que o falante está inserido.

Portanto, as práticas de linguagem (oralidade, escuta, leitura, escrita, reflexão linguístico-discursivo-semiótica) são demandadas para viabilizar a aprendizagem de línguas. Ao pensar nessas práticas, temos de levar em consideração preceitos teóricos e metodológicos que viabilizam os estudos de letramento, a fim de termos subsídios para examinar coerentemente as mudanças das práticas sociais. Em termos de ensino de LE, essas práticas sociais movimentam e modificam a língua e, consequentemente, a linguagem e seus usos.

De acordo com Barton e Lee (2015: 27), devido à globalização, essas mudanças são mais frequentes, pois estão associadas às práticas locais e globais e estão vinculadas às ferramentas tecnológicas disponíveis para desenvolver as atividades "letradas", o que evidencia um tipo específico de letramento: os letramentos digitais.

Ribeiro (2016:163) destaca que o letramento digital demanda competências e habilidades que se adéquem ao meio digital e possam produzir sentido a partir deles. Em outras palavras, desenvolver os letramentos digitais significa aprender a utilizar as tecnologias digitais, compreendê-las e relacioná-las aos valores dos grupos sociais (cibercultura), modificando os modos de ler e escrever por meio dos recursos digitais da internet.

De acordo com Coscarelli (2016), o ensino de línguas é influenciado pelas práticas digitais, pois, no âmbito da internet, o processo de ensino-aprendizagem desfruta de recursos que podem ser adaptados para a sala de aula. E, para usufruir desses recursos, passa a adotar uma perspectiva discursiva da linguagem e se preocupa com o desenvolvimento do letramento digital dos alunos. Vale frisar que os letramentos digitais consistem em habilidades para produzir associações e compreensões nos espaços multimidiáticos (ZACHARIAS, 2016), portanto são moldados e envolvidos por textos e práticas que passam a ser vinculados pela internet, impetrando assim uma compreensão mais “aberta" do termo "texto", para além de ser fixo e estável, passando a ser entendido como fluidos, interativos e multimodais. Esta percepção de texto nos direciona as questões referentes aos multiletramentos.

Segundo Rojo (2012:13), o que caracteriza os multiletramentos são: “a multiplicidade cultural das populações e a multiplicidade semiótica de constituição dos 
textos por meio dos quais ela se informa e se comunica." Sem nos desfazermos da importância da primeira, pois ela é também determinante para o ensino de LE, voltamonos à segunda, que parece estabelecer uma conexão entre os termos multiletramentos e multimodalidade. O texto é composto de diversas semioses, que exigem uma capacidade do leitor para inferir os potenciais efeitos de sentido. Às capacidades de analisar e de produzir sentidos damos o nome de multiletramentos.

Portanto, a noção de multiletramentos passa a estabelecer novas práticas de linguagem, na dimensão da produção, circulação e de recepção de textos, já que os modos de produzir sentidos se modificam de acordo com os sujeitos e os diferentes processos interlocutivos. Os multiletramentos evidenciam o caráter interativo, colaborativo, cooperativo, híbrido e subversivo da linguagem. Isto posto, reiteramos que, de acordo com Rojo (2012), os termos multimodalidade e multiletramentos estão intrinsecamente ligados e fortemente direcionados ao contexto de ensino mediado pela tecnologia digital.

Tentando compilar toda essa diversidade de conceitos e inseri-los no campo de conhecimento voltado para o ensino de LE, tendo-o fortemente influenciado pelo uso das tecnologias digitais, é relevante asseverar que os métodos e abordagens já préestabelecidos para esse tipo de ensino também sofreram adaptações. Por essa razão, espera-se do profissional que ensina uma competência linguístico-discursiva e técnica associada a um conhecimento prático do uso da língua nos meios digitais.

Por essa razão, o ensino de LE da contemporaneidade deve levar em consideração os modos comunicativos e os modos semióticos dispostos na internet ou nos recursos digitais que as pessoas mobilizam para aprender a língua (BARTON e LEE, 2015). A construção de sentido sobre o conteúdo a que o aluno está sendo exposto é uma das principais condições para efetivar a aprendizagem de LE. Dessa forma, os aprendizes passam a ser capazes de combinar os usos dos recursos semióticos (linguagem, imagem, textos, vídeos, cores, formas, fontes) de outras maneiras, diferentes das pré-estabelecidas culturalmente, e com isso poderão ser capazes de inventar ou modificar as relações entre língua, linguagem e outros modos de construção de sentidos.

Para o ensino de LE, construir sentido por meios multimodais é uma maneira de posicionar a si mesmo e aos outros e essa postura acaba por corroborar a modificação 
dos métodos e abordagens de ensino de LE já existentes. O ensino de LE no contexto multimodal deve prever, além do desenvolvimento das habilidades cognitivas da língua, o seu propósito e diversidade enquanto prática social.

Considerando o exposto e o propósito de investigação que originou este artigo, nos deteremos a conjecturar sobre as escolhas multimodais feitas por professores préserviço quando apresentaram uma proposta de ensino de língua inglesa, como tarefa avaliativa de uma disciplina no contexto de formação de professores e as diferentes multimodalidades apresentadas por eles quando analisaram essas aulas.

\section{Considerações metodológicas}

A investigação que norteou a geração dos dados está vinculada ao projeto de pesquisa: Ensinar e aprender utilizando a Internet como fonte e meio de material didático, que compõe os trabalhos do grupo de pesquisa em Tecnologias e Práticas Digitais no ensino-aprendizagem de línguas. O recorte para este artigo consiste na análise de diálogos online estabelecidos por professores pré-serviço no final do seu curso de graduação, quando em contato com o ensino de línguas mediado pelas tecnologias digitais.

Seguindo os padrões da pesquisa qualitativa e etnográfica que normalmente norteiam os trabalhos na área da Linguística Aplicada, os dados foram gerados e coletados durante o primeiro semestre letivo de uma disciplina no ano de 2018 , que teve por objetivo propiciar um contato teórico e prático dos licenciandos com as tecnologias digitais visando a uma formação teórico-prática reflexiva.

Especificamente sobre os participantes da pesquisa, podemos afirmar que os alunos constituíam um grupo heterogêneo de vinte e cinco pessoas com habilidades linguísticas distintas. Todos deveriam cumprir com a tarefa avaliativa e também deveriam participar do fórum (no Moodle - plataforma onde a disciplina estava hospedada e sendo oferecida).

Solicitados a aplicarem uma atividade de ensino de língua inglesa, abordando qualquer uma ou mais habilidades linguísticas que fizessem uso das tecnologias digitais, os professores pré-serviço tinham então, de utilizar seu conhecimento prévio sobre o processo de ensino de língua estrangeira supramencionado, e selecionar material/ambiente disponível na internet, planejar, elaborar e executar a atividade dentro 
de um laboratório de informática com computadores conectados à rede. Como mencionado anteriormente, o objetivo da disciplina é fazer com que esses futuros professores tenham contato com uma diferente forma de executar uma atividade para um contexto de ensino - laboratório de informática, oferecendo assim, uma oportunidade de utilizar diferentes tecnologias, incluindo textos, imagens, sons e, porque não dizer, movimentos em benefício do ensino de línguas.

Vale destacar que a atividade deveria ser realizada individualmente nos dias e horários marcados pela professora da disciplina. Desse modo, em um mesmo horário da aula, mais de uma atividade foi aplicada, visto que cada uma não poderia se estender por mais de quinze minutos. E, após a realização das atividades, os professores préserviço deveriam comentá-las voltando suas argumentações para os contextos teóricos estudados sobre o ensino-aprendizagem de línguas mediado pelas tecnologias digitais. São esses comentários que serão analisados neste artigo. Importante mencionar que eles serão reproduzidos do mesmo modo como foram originalmente postados pelos participantes da pesquisa, sem nenhum ajuste ortográfico, de concordância ou ainda dos erros de digitação.

Demarcando os traços da multimodalidade e dos multiletramentos nos comentários produzidos, por meio da identificação das escolhas lexicais dos participantes, buscamos compreender questões relacionadas ao nível de letramento digital e crítico dos participantes, bem como a apropriação deles pelos participantes. Esse levantamento, portanto, nos auxiliará nas conjecturas sobre o processo de formação no qual estão inseridos frente aos desafios do ensino de LE em múltiplos contextos.

\section{Discussão e análise dos dados}

Conforme exposto na seção de metodologia, serão apresentados alguns excertos dos comentários sobre as atividades propostas pelos professores pré-serviço. Como supramencionado os excertos foram selecionados visando a elucidar momentos em que surgem as menções sobre as possibilidades multimodais para o desenvolvimento das atividades de ensino e, por consequência, a necessidade de acionar os multiletramentos.

A fim de sistematizar a apresentação dos excertos, decidimos por primeiro apresentar a proposta e depois alguns comentários sobre a atividade. Começamos com 
uma atividade que propõe o desenvolvimento das habilidades linguísticas de ouvir e falar, por meio do Youtube. O participante 1, ao apresentar os objetivos da atividade, menciona:

a) Aproveitar os recursos interativos disponíveis na internet e os recursos tecnológicos da instituição de ensino, para despertar o interesse e engajar os alunos no estudo de inglês.

b) Trabalhar a oralidade em inglês por meio da interação entre os colegas, dispostos em duplas.

Ao apresentar a atividade, o professor em pré-serviço orienta:

"Os alunos ligam seus fones de ouvido e acessam o link do jogo interativo
"Who Wantstobe a Youtubillionaire" (...) As duplas assistem os vídeos em
inglês, (...) com perguntas aleatórias e quatro opções de resposta. Os alunos
devem debater as perguntas entre si, em inglês, e escolher uma opção de
resposta para clicar. A opção clicada irá encaminhar a dupla para o
próximo vídeo. Caso tenha selecionado a resposta errada, a dupla deverá
voltar ao vídeo anterior e tentar novamente até acertar a resposta. Assim
consecutivamente até acabarem os vídeos ou o tempo para a realização da
atividade."

Observando as escolhas lexicais do participante 1 em destaque, podemos perceber que ao anunciar a atividade ele já acena para a necessidade dos alunos acionarem seus letramentos digitais, visto que, para executar a atividade, os alunos devem ter a competência e a habilidade adequada ao meio digital e a partir delas eles vão conseguir produzir o conhecimento de conteúdo esperado. Essa expectativa do participante 1 está diretamente relacionada ao que Ribeiro (2016) menciona sobre o letramento digital, que por sua vez está integrado ao universo da cibercultura.

Outro ponto que precisa ser destacado nos "comandos" do participante é a escolha de trabalhar com vídeos. Ao fazer essa escolha, ele pressupõe capacidades que vão além do letramento digital, acionando as capacidades e habilidades multimodais, visto que o recurso didático oferece várias semioses, tais como: imagem, movimento, gestos, e principalmente um áudio de um falante nativo, cuja compreensão é desafiadora para os aprendizes de língua inglesa.

Após a execução da atividade, os colegas comentaram suas experiências de aprendizagem no fórum do ambiente virtual onde a disciplina da graduação está hospedada. Os destaques nos excertos abaixo elucidam alguns fatores que retratam o processo de ensino mediado pela tecnologia digital e a posição deles enquanto futuros 
professores, mas também é possível perceber nestes destaques que esse momento de discussão promove um letramento crítico sobre a experiência vivenciada.

\begin{abstract}
Aluno A: A atividade é divertida e por ser um falante nativo proporciona o contato com a língua de forma autêntica. O único ponto que tive dificuldade foi em relação ao próprio vídeo. Se não clicarmos rápido o YouTube joga para outra coisa totalmente diferente, penso que essa observação seria interessante.
\end{abstract}

Aluno B: Foi a atividade que mais tive dificuldade por o apresentador ser um falante nativo. Com certeza aplicaria em uma docência, com as devidas adaptações para a turma.

Aluno C: Também, particularmente, percebi a grande facilidade de uso do recurso, afinal, é comum o acesso a sites de vídeos, como o que foi utilizado, o Youtube, para busca de informações em audiovisual. Desse modo, não há necessidade de tanta presença do professor, o que desponta como mais uma grande vantagem do uso de CALL.

Analisando os excertos, temos a seguinte configuração: Todos eles destacam os efeitos da multimodalidade e, por conseguinte a necessidade de acionar os multiletramentos. Aqui podemos também especificar esses multiletramentos ao letramento digital e crítico. Especificamente no excerto do Aluno A podemos inferir que ele não tem a habilidade digital necessária para a execução da tarefa, pois assinala a dificuldade em "clicar rápido". No excerto do Aluno B, percebemos a questão da habilidade linguística que ele julga não ter em função de ser um vídeo com um falante nativo. Outro detalhe importante é o destaque para o letramento crítico e por que não dizer desenvolvimento didático-pedagógico esperado quando ele consegue visualizar a possibilidade pedagógica para "replicar" a atividade sem sua sala de aula, mas principalmente resguardando a probabilidade de readequação. Probabilidade esta com certeza em função do grau de dificuldade linguística vivenciada por ele. Ou seja, percebe-se no comentário desse aluno que ele já começa, ainda em sua formação, a pensar nos desafios de se utilizar a tecnologia digital para o ensino de língua estrangeira, assim como o esperado pelos autores (SILVA e CAMARGO, 2015; SUNAGA e CARVALHO, 2015; ALBUQUERQUE-COSTA e MAYRINK, 2015) que se preocupam com a participação do aprendiz no processo de ensino-aprendizagem da LE.

Já no excerto do Aluno C, percebe-se que ele não tem a mesma dificuldade de letramento digital que o Aluno A apresenta. Ele reconhece a multimodalidade do 
recurso utilizado quando faz menção às informações audiovisuais do artefato e ainda consegue analisar a relação da atividade com os preceitos teóricos estudados na disciplina que dizem respeito à área do conhecimento conhecida como CALL (Computer Assissted Language Learning), que em português é Aprendizagem de Línguas Mediada pelo Computador, pontuando o que autores como Levy (1997), Paiva (1997), Hubbard (2004), Braga (2013), Autora (2014), Leffa (2016), postulam sobre o potencial do ensino multimídia para o ensino de línguas.

O segundo exemplo de atividade propõe o desenvolvimento das habilidades linguísticas que envolvem a leitura e a escrita. O participante 2 propõe atividades que envolvem a leitura de cardápios online e ao apresentá-las dá destaque aos seguintes objetivos:
a) "desenvolver a compreensão escrita dos alunos em meio virtual;"
b) "trabalhar situações de leitura específica e leitura geral por meio de perguntas geradoras;"

Ao apresentar a metodologia da execução da atividade ele diz:

\footnotetext{
"O professor levará os alunos até a sala de informática e os dividirá conforme o número de equipamentos disponíveis. (...) O objetivo aqui é fazem com que os alunos visitem os menus dos restaurantes para encontrar uma informação específica, por exemplo, vendo quais deles realmente oferecem "schrimp". Após esta etapa, todos produzirão pequenas frases utilizando o novo vocabulário adquirido, seguindo perguntas que os farão comparar as informações recebidas por meio das palavras e das imagens presentes nos sites visitados. (...) $\mathrm{O}$ professor também fará perguntas que os levem a perceber, por meio da leitura dos menus dos restaurantes características desses sites. (...)

Indicações de restaurantes

http://www.mamas-sf.com/- San Franciso - California https://fogodechao.com/menu - Dallas - Texas https://www.danielnyc.com/ - New York - New York https://www.lovelesscafe.com/eat/menus - Nashville - Tenessee https://cocobambu.com/usa/ - Miami - Florida"
}

Analisando a proposta didática do participante 2, percebemos que embora ele solicite a execução da atividade no laboratório de informática, com uso de internet, para obter as informações necessárias, não está explicitada a forma de entrega da atividade (caderno, documento de editor de texto ou no próprio site visitado), nem a estratégia a ser utilizada pelo professor para dar ofeedback.

Dessa forma, é possível considerar que, ao planejar a aula, o participante 2 avalia as questões da multimodalidade para o ensino de língua inglesa, pois faz menção às “informações recebidas por meio das palavras e das imagens presentes nos sites 
visitado", mas não consegue acionar o seu letramento crítico que, segundo Green (1998), demanda dos indivíduos mais do que fazer uso de práticas de letramento, mas principalmente transformar essas práticas ao propor a finalização da atividade.

Essa falta foi compensada por uma discussão sobre as experiências de aprendizagem. Nesse momento, os destaques se direcionaram para o letramento crítico, dado o enfoque na transformação das práticas, em detrimento do uso de recursos, conforme se verifica a seguir:

\begin{abstract}
Aluno B: "A proposta é muito interessante. Utilizar sites que possuem sede nos Estados Unidos trabalham aspectos culturais. Eu acredito que uma atividade de compreensão global possa ser interessante durante o processo. Todos os alunos podem comentar o que compreenderam dos sites. Quais refeições eles já conheciam, quais aspectos são diferentes. Dessa forma, eles começariam pelo que já conhecem e inferem outros aspectos."
\end{abstract}

Aluno D: "Essa atividade possibilita a exploração de diversos sites. Acredito que como forma de motivar os alunos, a proposta inicial seja interessante, mas pensando em uma forma de avaliar o processo de aprendizagem dos estudantes, os sites e as perguntas poderiam ser mais delimitadas, por exemplo, trabalhar com um restaurante com pratos mais caros e um restaurante com pratos mais baratos, a fim de comparar esses alimentos. Sobre a escolha do vocabulário, os alunos poderiam selecionar uma das palavras e explorá-la no site escolhido por eles, realizando um trabalho de produção escrita, escrevendo algo sobre o item que identificou, ou realizando um trabalho com a produção oral, relatando a relação do vocabulário selecionado e o restaurante."

Aluno E: "Achei bem interessante os sites que você apresentou, além de trabalhar aspectos da língua inglesa possibilita ao aluno viajar por restaurantes que ele não tem acesso. A atividade pode ser explorada de várias formas de acordo com o nível do aluno, ou seja, ensino fundamental e ensino médio. Na minha opinião, a atividade poderia ser feita em dupla, o professor daria um tempo para navegarem e conhecerem os sites e depois pediria para os alunos fazerem atividade de speaking relatando o que encontraram, qual restaurante gostaria de conhecer, qual prato já experimentou ou gostaria de experimentar etc. E depois poderiam trocar as duplas para compartilharem suas impressões."

O terceiro exemplo de atividade a ser apresentado neste recorte também está direcionado às habilidades de leitura e escrita. Pensada e executada em dupla, os participantes 3 e 4 , ao apresentarem os objetivos da atividade, mencionam:

a) "Trabalhar a possibilidade de escrita em um ambiente tecnológico a partir de um espaço interativo, e possibilitar o trabalho em grupo e a criatividade na execução de tarefas em prol do desenvolvimento de Língua Inglesa."

b) "Apresentar o site e suas potencialidades"

c) "Promover um momento de escrita a partir de um gênero literário"

d) "Incentivar a leitura de histórias escritas em Língua Inglesa" 
Ao apresentarem a metodologia da execução da atividade eles propõem:

\begin{abstract}
"WordShake - Seleção de palavras - Os estudantes entrarão no site https://learnenglish.britishcouncil.org/en/games/wordshake, e jogarão uma rodada do game. As palavras encontradas pelos alunos nortearão a escrita deles.

4 THE WORDS “Onceupon a time..." - Nesse tópico, os estudantes entrarão no site https://4thewords.com/ e em duplas criarão um novo projeto de escrita. Nesse projeto, eles utilizarão o modelo "Once upon a time" para escrever uma história inserindo as palavras encontradas no wordshake. Os alunos irão enviar suas produções para o nosso e-mail, a fim de que possamos realizar o feedback com eles na segunda aula."
\end{abstract}

Ao observarmos os objetivos e os procedimentos metodológicos da dupla, percebemos que os proponentes da atividade, pelas orientações propostas, evidenciam um domínio relativo sobre o uso do artefato tecnológico em benefício do processo de ensino-aprendizagem de língua inglesa. Observa-se uma capacidade de propor uma atividade que está diretamente ligada à produção escrita, que é totalmente embasada em um processo autônomo de construção do conhecimento por meio de uma contextualização, buscando uma aprendizagem significativa e totalmente ancorada nas tecnologias digitais. Além disso, foi proposta uma tarefa que também levasse em consideração a execução de uma aprendizagem colaborativa, como pode ser comprovado no destaque - "possibilidade de escrita em um ambiente tecnológico a partir de um espaço interativo, e possibilitar o trabalho em grupo e a criatividade na execução de tarefas".

No que diz respeito aos comentários dos alunos após a experiência, temos os seguintes destaques:

\footnotetext{
Aluno C: “(...) Tive um pouco de dificuldade para me lembrar das palavras que consegui escrever, eu não anotei nada! Com relação à história, consegui me lembrar de vários contos e tentei adaptá-los de forma que ficasse um pouco mais original. Tive dificuldades também para lembrar de palavras relacionadas ao tema proposto, mas tudo correu bem. Eu sempre gostei de histórias infantis, e o site que vocês usaram possui muitas cores e recursos, o que me instigou a escrever tudo de que me lembrara."

Aluno F: "Eu adorei o plano de aula de vocês, inclusive estou viciada! É uma atividade que exige a escrita de uma forma que não é imposta, mas dinâmica. Achei o aplicativo ótimo, muito instigante mesmo e diferente. Com certeza usaria em sala de aula."
}

Os excertos acima também oscilam entre dar destaque ao letramento digital e o letramento crítico dos professores pré-serviço que vivenciaram a experiência de 
aprendizagem de língua inglesa oferecida pela dupla. Damos especial destaque aos comentários do Aluno C, que elucida características mencionadas por Barton e Lee (2015), sobre o fato de que ensino de LE da contemporaneidade deve levar em consideração os modos comunicativos e os modos semióticos dispostos na internet ou nos recursos digitais que as pessoas mobilizam para aprender a língua. No comentário, percebe-se que o aprendiz foi capaz de combinar os usos dos recursos semióticos (linguagem, imagem, textos, vídeos, cores, formas, fontes) de outras maneiras do que as pré-estabelecidas culturalmente e com isso construir sentido para sua aprendizagem.

Nesse contexto, Rojo (2012) discorre sobre a multiplicidade semiótica de constituição dos textos. Segundo a autora, essa multiplicidade semiótica permite interações diferenciadas e é exatamente o que foi colocado pelo Aluno F quando menciona: "atividade que exige a escrita de uma forma que não é imposta, mas dinâmica. Achei o aplicativo ótimo, muito instigante mesmo e diferente." Além disso, ao teorizar reflexivamente sobre a experiência de ensino-aprendizagem vivenciada, percebe-se que os participantes demonstram ter habilidades relevantes para o ensino de línguas em relação ao letramento digital e conseguem visualizar novas possibilidades de explorar a multimodalidade para e na execução das atividades de ensino propostas.

Retomando o que foi apresentado na seção teórica deste artigo, destacamos a afirmação de Coscarelli (2016), que assevera que o ensino de línguas atualmente é influenciado pelas práticas digitais e, por essa razão, desfruta de recursos na internet que podem ser adaptados para a sala de aula e/ou utilizados como sala de aula. Portanto, a partir dos exemplos de atividades apresentados neste artigo, reiteramos a relevância de os professores de línguas terem contato com a experiência de ensino mediado pela tecnologia digital ainda em seu processo de formação.

Essa experiência os auxiliará a usufruir dos recursos digitais - letramento digital - bem como a desenvolver um letramento crítico que os ajude a adotar uma perspectiva mais discursiva da linguagem e também se preocupar com o desenvolvimento do letramento digital dos alunos, focando em um ensino de língua mais comunicativo e rico em textos multimodais. 


\section{Considerações finais}

Apresentadas as experiências de formação docente em relação ao ensino de língua inglesa mediado pelo computador, percebemos que os participantes utilizam as mídias digitais e seus recursos para o ensino de LE buscando não só oportunizar contato com o conteúdo, mas principalmente, estimular as práticas de letramento digital. Interessante destacar que os participantes também consideraram as práticas de letramento extracurriculares, ou seja, as experiências prévias que os alunos já possuíam, bem como suas habilidades multimodais em benefício da execução das suas atividades de ensino de língua.

Com essa postura didático-pedagógica percebemos que os participantes puderam oferecer também uma oportunidade para os colegas refletirem sobre como articular suas próprias teorias e experiência de vida para aprender online e, por conseguinte, serem capazes de pensar em como ensinar a partir da experiência vivenciada no contexto acadêmico. Essa postura crítico-reflexiva transforma as atividades de ensino propostas, e elas embora dirigidas, passam a permitir certa liberdade, ou seja, um espaço autônomo e de cooperação entre os alunos que a estão realizando.

Dessa forma, podemos afirmar que os desafios e as complexidades que envolvem o ensino de LE, percorrem não só os contextos de atuação, mas também os de formação desses professores. Por essa razão é importante focar em uma visão social prática de letramentos que visem auxiliar o processo de ensino-aprendizagem de línguas, visto que, conforme apresentado no escopo deste artigo, atividades de ensino mediadas pela tecnologia podem revelar como os alunos percebem, aproveitam e (re)significam as virtualidades dos espaços digitais de acordo com suas identidades culturais e linguísticas.

Conhecer as experiências de ensino apresentadas neste artigo é importante não só para os professores em formação, como também para a comunidade acadêmica que está preocupada com os novos rumos que o ensino de língua inglesa irá galgar devido às mudanças contextuais, sociais e "virtuais" que viabilizam esse ensino. Mudanças essas que rompem com as fronteiras entre os domínios de uma atividade pedagógica e passam a demandar multiletramentos distintos, além de uma visão social e cultural diferenciada do ensino de língua inglesa. 


\section{Referências}

ALBUQUERQUE-COSTA, H.; MAYRINK, M. F. A extensão da sala presencial para o Moodle: Espaço de aprendizagem, reflexão e pesquisas nos cursos de letras Francês e Espanhol da USP. In: SILVA, K.A.; MASTRELLA-DE-ANDRADE, M; Pereira Filho, C. A. (orgs). A formação de professores de línguas: políticas, projetos e parcerias. Campinas, SP: Pontes, 2015.

BARON, N. Literacy: an introduction to the Ecology of written Language. Oxford: Blackwell, 1994.

BARTON, D; LEE, C. Linguagem online: textos e práticas digitais. São Paulo: Parábola Editorial, 2015.

BRAGA, D. B. Ambientes digitais: reflexões teóricas e práticas. São Paulo: 2013. $146 \mathrm{p}$.

BRYDON, D. Local Needs, Global Contexts: Learning New Literacies. In: MACIEL, R. F.; ARAÚJO, V. A. (Orgs). Formação de professores de línguas: ampliando perspectivas. Jundiaí: Paco Editora, 2011.

COSCARELI, C. V. Tecnologias para aprender. São Paulo: Parábola Editorial, 2016. p. 192.

ELLIS, R. Second language acquisition. Oxford: Oxford University Press, 1997.

GREEN, B. Subject-specific literacy and School learning: a focus on writing. Australia Journal of Education, 30(2) 1998: p. 156-69.

HUBBARD, P. Linguistics and the Teaching of English as a Second/Foreign Language. 2004. Disponível em: http://www.stanford.edu/class/linguist289/call1.htm. Acesso em 10 out 2017.

KURAMAVADIVELU, B. Understanding Language Teaching: from Method to Postmethod. Mahwah, N. J: Lawrence Erlbaum Associates, 2006.

LEFFA, V. J. Língua estrangeira. Ensino e aprendizagem. Pelotas: EDUCAT, 2016.

LEVY, Michael. Computer-assisted language learning. Oxford: Claredon, 1997.

PAIVA, V. L. M. O uso da tecnologia no ensino de línguas estrangeiras: breve retrospectiva histórica. In: JESUS, D. M. de; MACIEL. R. F. (Orgs.). Olhares sobre tecnologias digitais: linguagens, ensino, formação e prática docente. v. 44. Campinas, SP: Pontes, 2015, p. 21-34.

PAIVA, V. L. M. O. As letras na Internet. Cadernos de Pesquisa do NAPq. Belo Horizonte: Fale, UFMG, n. 35, maio de 1997.

RIBEIRO, A. L.; Jogos online no ensino-aprendizagem da leitura e da escrita. In: COSCARELI, C. V. Tecnologias para aprender. São Paulo: Parábola, 2016. p. 159-174 
RICHARDS, J.C.; RODGERS, T.S. Approaches and Methods in Language Teaching: a Description and Analysis. Cambridge: Cambridge University Press, 1993.

SILVA, R. A. da; CAMARGO, A. L. A cultura escolar na era digital: o impacto da aceleração tecnológica na relação professor-aluno, no currículo e na organização escolar. In: BACICH, L; TANZI NETO, A.; TREVISANI, F. de M. Ensino híbrido: personalização e tecnologia na educação. São Paulo: Penso, 2015. p. 169-190.

SUNAGA, A.; CARVALHO, C. S. de. As tecnologias digitais no ensino híbrido. In: BACICH, L.; TANZI NETO, A.; TREVISANI, F. de M. Ensino híbrido: personalização e tecnologia na educação. São Paulo: Penso, 2015. p. 141-154.

ZACHARIAS, V. R. C. de. Letramento Digital: desafios e possibilidades para o ensino. In: COSCARELI, C. V. Tecnologias para aprender. São Paulo: Parábola, 2016. p. 1629.

Recebido em: 30 out. 2018.

Aceito em: 23 abr. 2019. 